\title{
Reliability and practical aspects of the disease impact measure on hypertensive patients ${ }^{1}$
}

\author{
Renata Bigatti Bellizzotti Pavan² \\ Kátia Melissa Padilha ${ }^{3}$ \\ Simey de Lima Lopes Rodrigues ${ }^{2}$ \\ Roberta Cunha Matheus Rodrigues ${ }^{4}$ \\ Maria Cecilia Jayme Bueno Gallani ${ }^{5}$
}

Objective: to evaluate the feasibility, acceptability, the ceiling and floor effects and the reliability of the Instrument to Measure the Impact of Coronary Disease on Patient's Daily Life (IDCV) when applied to hypertensive patients. Method: one hundred and thirty seven hypertensive outpatients were interviewed, using questionnaires to collect sociodemographic and clinical data, followed by the IDCV. Reliability was assessed according to the temporal stability and internal consistency criteria. Results: the IDCV was applied in $8.0( \pm 3.0)$ minutes with $100 \%$ of the items answered. A ceiling effect of $31.4 \%$ was observed in the domain Adjustment to the Disease. The stability measure was observed for the total score and for all domains. There was evidence of internal consistency of the total IDCV $(\alpha=0.83)$ and the domains Physical Impact of the Disease - Symptoms $(\alpha=0.78)$ and Social and Emotional Impact of the Disease $(\alpha=0.74)$. Conclusion: the IDCV is an instrument of easy use and its reliability among hypertensive patients is evidenced. The domain Adjustment to the Disease, however, should be reviewed in further studies.

Descriptors: Nursing; Hypertension; Sickness Impact Profile.

\footnotetext{
${ }^{1}$ Paper extracted from master's thesis "Validation of an instrument to measure the impact of the disease in daily valvopata - IDCV in patients with hypertension" presented to Faculdade de Enfermagem, Universidade Estadual de Campinas, Campinas, SP, Brazil.

Corresponding Author:

Renata Bigatti Bellizzotti Pavan

Universidade Estadual de Campinas. Faculdade de Enfermagem

Caixa Postal 6111

Rua Tessália Vieira de Camargo, 126

Cidade Universitária Zeferino Vaz

Distrito de Barão Geraldo

CEP: $13083-887$, Campinas, SP, Brasil

E-mail: renata.bigatti@gmail.com

Copyright (c) 2013 Revista Latino-Americana de Enfermagem This is an Open Access article distributed under the terms of the Creative Commons Attribution Non-Commercial License (CC BY-NC).

This license lets others distribute, remix, tweak, and build upon your work non-commercially, and although their new works must also acknowledge you and be non-commercial, they don't have to license their derivative works on the same terms. 


\section{Introduction}

Systemic Arterial Hypertension (SAH) is currently considered one of the main chronic diseases in the world and one of the greatest public health challenges ${ }^{(1)}$. In the last few years, SAH has been increasingly predominant and a major risk factor for cardiovascular diseases ${ }^{(1-2)}$.

In a systematic review that included 44 studies in 35 countries, held from 2003 to 2008, a global predominance of SAH was shown in $37.8 \%$ of men and in $32.1 \%$ of women(3). In Brazil, in 2010 , data collected from DATASUS pointed out that $23.3 \%$ of the population over the age of 18 reported previous medical diagnosis of hypertension (weighted percentage to adjust the socio demographic distribution of VIGITEL sample to the distribution of the adult population of Census 2000) (4). A study involving the elderly population showed that $34.9 \%$ of all reported diseases referred to self-reported hypertension ${ }^{(5)}$.

The main purpose of treating SAH is to reduce the morbidity and mortality associated with high levels of blood pressure. The benefits of this treatment in relation to this reduction are effectively demonstrated. It is estimated that $40 \%$ of cerebrovascular accidents and about $25 \%$ of strokes in hypertensive patients can be prevented with appropriate anti-hypertensive therapy ${ }^{(3)}$.

Despite the clinical benefits provided by the treatment, anti-hypertensive medications can have adverse effects, as well as the SAH itself, considering that the stigma of the diagnosis and the impact of its clinical expression may affect the pleasure of living(6). Therefore, one important aspect in the assessment and approach of hypertensive patients is the health related quality of life (HRQoL).

A baseline study carried out with hypertensive patients showed a reduced HRQoL among hypertensive patients when compared to the group without hypertension. When associating $\mathrm{SAH}$ with other comorbidities, an additional reduction of the HRQoL could be observed ${ }^{(7)}$. These results indicate two important findings. The first relates to the importance of assessing the HRQoL of patients with cardiovascular diseases. The second is related to the relevance of providing a measure that is applicable to patients with cardiovascular diseases, with the purpose of measuring the same HRQoL construct and permitting intergroup comparison.

In the international literature, there are few specific instruments to assess the HRQoL of hypertensive patients, with emphasis on the Hypertension
Health Status Inventory - HYPER $31^{(8)}$, the Arterial Hypertension Quality of Life Questionnaire - Calidad de Vida en la Hipertensión Arterial - $\mathrm{CHAL}^{(9)}$ and its reduced version of the Mini-Cuestionario de Calidad de Vida en la Hipertension Arterial - Minichal(10), which includes subjective aspects and somatic expressions, without restricting the evaluation of the effects of drug therapy on patients' HRQoL.

Several generic and specific instruments have been validated for the assessment of HRQoL in patients with heart diseases ${ }^{(11-12)}$, but studies aimed at measuring the perceived disease impact on the daily life of these people in a deeper way are rare.

In order to assess people's perception regarding the impact of the disease on daily life, the IDCV - Instrument to Measure the Impact of Coronary Disease on Patient's Daily Life - was developed, based on the Brazilian population, and is aimed at measuring the impact of coronary disease on patients ${ }^{(13)}$. This instrument was shown to be valid and reliable when used in coronary disease patients being treated at outpatient clinics $^{(14)}$.

After validation studies of the IDCV ${ }^{(14)}$, it was found that, due to the range of its items, it would also be possible to use the instrument in patients suffering from other cardiovascular diseases ${ }^{(15)}$. Thus, the study which applied the IDCV in patients with coronary artery disease was conducted. Interestingly, the IDCV showed good psychometric performance, with evidences of internal consistency and construct validity ${ }^{(16)}$, similar to the previous IDCV validation study involving coronary disease patients ${ }^{(14)}$.

These findings suggested a new perspective on the use of the IDCV and aroused the interest in also investigating its measuring properties in relation to other groups of cardiovascular diseases, which share the symptoms and the chronic nature, such as the SAH.

This study investigated the acceptability, feasibility, ceiling and floor effects, as well as the reliability of the instrument to measure the Impact of Coronary Disease on Patient's Daily Life when applied to hypertensive patients.

\section{Method}

\section{Place of study}

The study was developed at the hypertension outpatient clinic of a large university hospital and at the medical specialties outpatient clinic, both in the subspecialty of cardiology, located in two cities in the state of São Paulo. 


\section{Subjects}

One hundred and thirty seven hypertensive patients participated in this study, over the age of 18 , male and female, under regular treatment at the above mentioned outpatient clinics, with medical diagnosis of hypertension reported in their medical records for at least one year. Patients with comorbidities that influenced the HRQoL were excluded (cancer, AIDS, chronic obstructive pulmonary disease, systolic heart failure functional class III and IV), as well as those with coronary diseases and with a history of ischemic coronary event in the last six months. Patients with a history of coronary artery disease, but who were submitted to medical follow ups at the time of the research only due to arterial hypertension, were included. Patients with verbal understanding and communication incapacity were excluded. The sample size was established by considering the coefficient of 0.70 , error margin of 0.10 and $\alpha=5 \%(n=137)$.

\section{Data collection}

Data collection was carried out from August 2011 to January 2012, through individual interviews held in a private environment, in order to ensure the uniformity of information. The data were collected in two stages:

- First Stage (Tt): the data was initially collected by consulting the medical records of data related to socio demographic and clinical features and, then, the instrument IDCV was used.

- Second Stage (Trt): performed 7 to 21 days after the first stage (Tt). The IDCV was reapplied (retest) to 88 participants who had responded to the IDCV (test) in the first stage of data collection.

\section{Instrument}

Instrument to Measure the Impact of Coronary Disease on Patient's Daily Life - IDCV

This is a specific instrument used in studies to assess the perception of the disease impact. It is composed of two scales: the first (Part A), with 14 items, measures the perceptions related to the impact of the disease; the second scale (Part B), with 14 items, measures people's assessment of each consequence of the disease mentioned in the first scale (whether it occurs or not in their lives). The answers to the items are presented in the Likert scale format, with answers that vary from (1) strongly disagree to (5) strongly agree for Part A. In Part $B$, the answers in the Likert scale vary from (1) very poor to (5) very good. The items are grouped in four domains: (a) Physical Impact of the Disease Symptoms (items 11, 12 and 13); (b) Impact of the Disease on Daily Activities (items 5, 7, 9, 10 and 14); (c) Social and Emotional Impact of the Disease (items 2, 3, 4 and 6) and (d) Adjustment to the Disease (items 1 and 8). For each item assessed, the score is determined by the product of the scores obtained from Part $A$ and Part $B$, which can generate a minimum score of 1 and a maximum score of 25 . For the final calculation of the scores, items 1, 5 and 8 of Part A are inverted, since they reflect perceptions on the favorable impact of the disease. In Part B, the scores of all items are inverted and, the higher the score, the worse the assessment of patients about the statement ${ }^{(14)}$. The higher the score, the higher the negative impact perceived by people and, on the contrary, the lower the score, the lower the perceived negative impact of the disease ${ }^{(14)}$.

The total score of the IDCV is estimated based on the sum of all products obtained, and varies from 14 to 350 .

\section{Data analysis}

The data collected were entered into an electronic spreadsheet Software Excel for Windows 2010 through double entry, in order to ensure the quality and consistency of the data, and transferred to the program SAS - System for Windows (Statistical Analysis System), version 9.2. 2002 - 2008, for the analyses:

- Descriptive: Design of frequency tables, position and dispersion measures for the characterization of socio demographic and clinical data.

- Feasibility, acceptability and ceiling and floor effect: The feasibility of the IDCV was assessed through the time spent to complete the instrument. The practical aspects of the measure/acceptability were assessed by the percentage of unanswered items and the proportion of patients who had not answered all items(17). For the floor effect analysis, the percentage of patients who scored floor was calculated, that is, those who showed the worst $10 \%$ results in the IDCV, which are the $10 \%$ highest scores (which indicate higher negative impact of the disease) $)^{(17)}$, for both the total IDCV $(\geq 316.4)$ and for its domains (Physical Impact of the Disease Symptoms $\geq 67.8$, Impact of the Disease on the Daily Activities $\geq 113.0$, Social and Emotional Impact of the Disease $\geq 90.4$ and Adjustment to the Disease $\geq 45.2$ ). The percentage of patients who scored ceiling(17) was also estimated, that is, those who showed the $10 \%$ best possible results in the scale (thus, the lowest scores, which mean a lower negative impact: 
total score $\leq 47.6$, Physical Impact of the Disease - Symptoms $\leq 10.2$, Impact of the Disease on daily Activities $\leq 17.0$, Social and Emotional Impact of the Disease $\leq 13.6$ and Adjustment to the Disease $\leq 6.8$ ). Up to $25 \%$, it was considered moderate ceiling and floor effect and, higher than $25 \%$, it was considered substantial(18).

- Reliability: The reliability was assessed by estimating the measurement error, according to the temporal stability of the measure criterion, which is the consistency among repeated measures (test/retest) by means of the intraclass correlation coefficient and by internal consistency (Cronbach alpha coefficient) ${ }^{(16)}$. A Cronbach alpha coefficient $>0.70^{(19)}$ was considered as evidence of internal consistency, and a coefficient $>0.70^{(20-21)}$ of temporal stability.

\section{Ethical aspects}

This study received approval from the local Research Ethics Committee (Registration number 1116/2010), and all patients listed signed an Informed Consent Term.

\section{Results}

\section{Socio demographic and clinical data}

The socio demographic and clinical characteristics of the 137 participants are presented in Table 1 . The sample $(n=137)$ consisted mostly of women $(54.0 \%)$, with average age of $59.0( \pm 10.7)$, Caucasian $(70.8 \%)$, married $(67.2 \%)$, professionally inactive (65.0\%). The average education in years was $6.1( \pm 4.3)$ and individual and family income of $1.5( \pm 1.4)$ and 2.7 $( \pm 2.2)$ minimum salaries (MS) per month, respectively.

The studied group was characterized by the average time of 13.5 ( \pm 9.5$)$ years of history of $\mathrm{SAH}$; in relation to the associated clinical conditions, the most predominant was dyslipidemia (62.8\%), followed by past or current smoking (48.2\%) and diabetes mellitus (37.2\%).

The average Body Mass Index was 29.7 ( \pm 5.2$)$. All participants were using some type of antihypertensive medication, and $79.5 \%$ took Angiotensin Converting Enzyme Inhibitor (ACEI) or Angiotensin Receptor Blocker (ARB).

Table 1 - Socio Demographic and Clinical Characterization of Hypertensive Patients ( $n=137)$. Campinas, SP, Brazil, 2012

\begin{tabular}{|c|c|c|c|c|c|}
\hline Socio demographic Variables & $\mathbf{N}$ & $\%$ & Average (sd*) & Median & Variation \\
\hline Age (in years) & & & $59.8(10.6)$ & 60 & $21-87$ \\
\hline Gender (female) & 74 & 54 & & & \\
\hline Race (Caucasian) & 97 & 70.8 & & & \\
\hline Education & & & $6.1(4.3)$ & 5 & $0-21$ \\
\hline Marital Status (with partner) & 102 & 74.5 & & & \\
\hline \multicolumn{6}{|l|}{ Employment Status } \\
\hline Inactive & 93 & 67.8 & & & \\
\hline Active & & 31 & 22.6 & & \\
\hline Housework & & 13 & 9.6 & & \\
\hline Monthly Individual Income $(\mathrm{MS})^{\dagger}$ & & & $1.5(1.4)$ & 1 & $0-7$ \\
\hline Monthly Family Income (MS) & & & $2.7(2.2)$ & 2 & $0-20$ \\
\hline \multicolumn{6}{|l|}{ Clinical Variables } \\
\hline Time of SAH (in years) & & & $13.5(9.5)$ & 11 & $1-50$ \\
\hline \multicolumn{6}{|l|}{ Target Organs Damage } \\
\hline Coronary artery disease & & 24 & 17.5 & & \\
\hline Kidney failure & & 17 & 12.4 & & \\
\hline Heart failure & & 10 & 7.2 & & \\
\hline Cerebrovascular accident & & 3 & 2.1 & & \\
\hline Hypertensive Retinopathy & & 1 & 0.7 & & \\
\hline \multicolumn{6}{|l|}{ Associated Clinical Conditions } \\
\hline Dyslipidemia & & 86 & 62.8 & & \\
\hline Smoking & & 66 & 48.2 & & \\
\hline Diabetes Mellitus & & 51 & 37.2 & & \\
\hline Peripheral vascular disease & & 12 & 8.7 & & \\
\hline Body mass index & & & $29.7(5.2)$ & 28.0 & $\begin{array}{l}17.2-48.1 \\
\text { (continu }\end{array}$ \\
\hline
\end{tabular}


Table 1 - (continuation)

\begin{tabular}{|c|c|c|c|c|c|}
\hline Socio demographic Variables & $\mathbf{N}$ & $\%$ & Average $\left(\mathbf{s d}^{*}\right)$ & Median & Variation \\
\hline \multicolumn{6}{|l|}{ Medications used per class } \\
\hline $\mathrm{ACEI} \mathrm{ARB}^{\ddagger}$ & & 109 & 79.5 & & \\
\hline Diuretic & & 80 & 58.4 & & \\
\hline Alpha/Beta blocker & & 61 & 44.5 & & \\
\hline Calcium channel blocker & & 43 & 31.4 & & \\
\hline Vasodilators & & 3 & 2.2 & & \\
\hline \multicolumn{6}{|l|}{ Hypertension severity } \\
\hline Excellent & & 15 & 11 & & \\
\hline Normal & & 28 & 20.4 & & \\
\hline Borderline & & 29 & 21.2 & & \\
\hline SAH - Stage 1 & & 44 & 32.1 & & \\
\hline SAH - Stages 2 and 3 & & 18 & 13.1 & & \\
\hline
\end{tabular}

*SD, standard deviation; †1 MS=R $\$ 510.00$ in Dec/2010; 1 MS=R $\$ 540.00$ from Jan/2011 to Dec/2011; 1 MS=R 622.00 in Jan/2012; $\neq A C E I$, angiotensin converting enzyme inhibitor; ARB, angiotensin receptor blocker

\section{Feasibility, Acceptability and Ceiling and Floor Effect and Descriptive Measures of the IDCV}

The average time to complete the IDCV at Tt was 8.0 ( \pm 3.0 ) minutes, ranging from 4.0 to 20.0 minutes. All patients answered $100 \%$ of the IDCV items, both at Tt and Trt, indicating high acceptability of the instrument. The descriptive measures of the IDCV, as well as the results of the assessment of the ceiling and floor effects, are shown in Table 2. The total IDCV score did not show a ceiling or floor effect. However, $31.4 \%$ of the participants scored "ceiling" in the Adjustment to the Disease domain.

\section{Reliability of the IDCV}

In order to assess reliability, the temporal stability and the internal consistency criteria presented in tables 3 and 4, respectively, were considered.

To assess temporal stability, the IDCV was reapplied to 88 patients at Trt, with an interval of 7 to 21 days. Satisfactory consistency indexes between the results of the two stages of use were found, as shown by the intraclass correlation coefficients. There was evidence of satisfactory internal consistency for the instrument as a whole (Cronbach alpha=0.83), as well as for two of its four domains: Physical Impact of the Disease - Symptoms (Cronbach alpha $=0.78$ ) and Social and Emotional Impact of the Disease (Cronbach alpha $=0.74$ ).

Table 2 - Descriptive analysis of ceiling and floor effects of the Instrument to Measure the Impact of Coronary Disease on Patient's Daily Life (IDCV) in hypertensive patients ( $n=137)$. Campinas, SP, Brazil, 2012

\begin{tabular}{|c|c|c|c|c|c|c|c|}
\hline Domain & $\begin{array}{l}\text { Average } \\
\text { (sd) }\end{array}$ & Median & Variation & Floor Effect* & Ceiling Effect ${ }^{\dagger}$ & $\begin{array}{c}\text { Floor } \\
\text { Effect \% }\end{array}$ & $\begin{array}{c}\text { Ceiling } \\
\text { Effect } \%\end{array}$ \\
\hline Physical Impact of the Disease - Symptoms & $38.5(21.1)$ & 49.0 & $12-75$ & Scores $\geq 67.8$ & Scores $\leq 10.2$ & 12.4 & - \\
\hline Impact of the Disease on Daily Activities & $58.1(23.4)$ & 64.0 & $18-110$ & Scores $\geq 113.0$ & Scores $\leq 17.0$ & - & - \\
\hline Social and Emotional Impact of the Disease & $45.1(24.0)$ & 54.0 & $15-100$ & Scores $\geq 90.4$ & Scores $\leq 13.6$ & 2.9 & - \\
\hline Adjustment to the Disease & $13.3(8.3)$ & 9.0 & $2-40$ & Scores $\geq 45.2$ & Scores $\leq 6.8$ & - & 31.3 \\
\hline Total - IDCV & $155.0(60.7)$ & 172.0 & $54-298$ & Scores $\geq 316.4$ & Scores $\leq 47.6$ & - & - \\
\hline
\end{tabular}

*Floor effect is equivalent to the $10 \%$ worst possible results in the scale; +Ceiling effect is equivalent to the $10 \%$ best possible results in the scale (Bennett, 2002)

Table 3 - Intraclass correlation coefficient (ICC) and respective reliability intervals (IC95\%) of the IDCV in patients with arterial hypertension $(n=88)$. Campinas, SP, Brazil, 2012

\begin{tabular}{|c|c|c|}
\hline Variable & ICC* & ICC $95 \%^{\dagger}$ \\
\hline Physical impact of the disease & 0.998 & {$[0.996-0.998]$} \\
\hline Impact of the disease on daily activities & 0.996 & [0.994-0.997] \\
\hline Social and emotional impact of the disease & 0.996 & [0.993-0.997] \\
\hline Adjustment to the disease & 0.994 & [0.991-0.996] \\
\hline Total IDCV & 0.998 & [0.998-0.999] \\
\hline
\end{tabular}

*Intraclass correlation coefficient; + Reliability interval of $95 \%$ 
Table 4 - Item-total correlation and Cronbach alpha coefficient of the Instrument to Measure the Impact of Coronary Disease on Patient's Daily Life (IDCV) in hypertensive patients( $n=137)$. Campinas, SP, Brazil, 2012

\begin{tabular}{|c|c|c|c|c|c|}
\hline Variable & $\begin{array}{l}\text { Total item } \\
\text { score/ } \\
\text { domains } \\
\text { correlation }\end{array}$ & $\begin{array}{l}\text { Item/total } \\
\text { score } \\
\text { correlation }\end{array}$ & $\begin{array}{l}\text { Cronbach } \\
\text { Alpha }\end{array}$ & $\begin{array}{l}\text { Cronbach } \\
\text { Alpha } \\
\text { of the } \\
\text { domain } \\
\text { if item } \\
\text { deleted }\end{array}$ & $\begin{array}{c}\text { Cronbach } \\
\text { Alpha of } \\
\text { the total } \\
\text { score } \\
\text { if item } \\
\text { deleted }\end{array}$ \\
\hline Total IDCV & & & 0.83 & & \\
\hline Physical Impact of the Disease - Symptoms & & & 0.78 & & \\
\hline 11 Due to the heart problem, I often have shortness of breath & 0.62 & 0.62 & & 0.70 & 0.81 \\
\hline 12 Due to the heart problem, I feel very tired & 0.64 & 0.57 & & 0.68 & 0.81 \\
\hline 13 Due to the heart problem. I often feel dizzy & 0.60 & 0.56 & & 0.73 & 0.81 \\
\hline Impact of the Disease on Daily Activities & & & 0.57 & & \\
\hline 5 I cope well with my heart problem & 0.20 & 0.86 & & 0.58 & 0.83 \\
\hline $\begin{array}{l}7 \text { After I got the heart problem, I started to fear that } \\
\text { something could happen to me }\end{array}$ & 0.44 & 0.44 & & 0.44 & 0.82 \\
\hline 9 Due to the heart problem, I have difficulty sleeping & 0.25 & 0.46 & & 0.56 & 0.82 \\
\hline 10 Due to the heart problem, I have a lot of difficulty performing daily tasks & 0.39 & 0.63 & & 0.48 & 0.81 \\
\hline 14 Having a heart problem concerns me & 0.39 & 0.32 & & 0.48 & 0.83 \\
\hline Social and Emotional Impact of the Disease & & & 0.74 & & \\
\hline 2 The heart problem made me become dependent on other people & 0.43 & 0.41 & & 0.74 & 0.82 \\
\hline 3 My heart problem affected my ability to work like before & 0.63 & 0.61 & & 0.63 & 0.81 \\
\hline 4 I now feel more irritated and stressed due to the heart problem & 0.60 & 0.62 & & 0.65 & 0.81 \\
\hline 6 I feel very anxious after I got a heart problem & 0.50 & 0.59 & & 0.71 & 0.81 \\
\hline Adjustment to the Disease & & & -0.01 & & \\
\hline 1 After I got a heart problem, I started to pay more attention to my health & - & 0.11 & & - & 0.83 \\
\hline 8 My sexual life remained the same as before I got the heart problem & & 0.15 & & & 0.84 \\
\hline
\end{tabular}

\section{Discussion}

This study was aimed at assessing the practical aspects of the measure in relation to the use of the IDCV in hypertensive patients, verifying its feasibility, acceptability, ceiling and floor effects and reliability. The findings showed that the use of the instrument in this group of patients is feasible.

The feasibility and acceptability are important aspects to be evaluated in relation to an instrument that is developed, adapted or tested in a population that is different from that it was originally developed for. The analysis of these properties permits verifying the instrument's feasibility for the new target population.

The study findings evidence these properties, since there is a low onus to the respondent as a result of the eight-minute average time for its use, besides the fact that no unanswered items were registered. These data show the IDCV performance in patients with coronary artery disease(15). However, it should be emphasized that, in both studies, the instrument was applied in the form of an interview, which can reduce the chances of unanswered items.

The analysis of the ceiling and floor effects, based on the analysis of the distribution of scores (total and domains), showed that the IDCV is an instrument potentially capable of detecting improvement or worsening in the perception of HRQoL over time(20).

The ceiling effect is confirmed when there is asymmetric distribution of scores and a significant percentage of the population in the study scores at the highest levels of the measure. This means that, if the subject who scored at the extreme range of the scale presents an improvement in the perceived HRQoL, the instrument will not be able to detect it.

The IDCV as a whole showed no ceiling effect, nor did its domains, except for Adjustment to the Disease, which showed a moderate ceiling effect, similar to the study undertaken with coronary disease patients $^{(15)}$. This means that the IDCV, when applied to hypertensive patients, is potentially capable of detecting improvements in the perception of HRQoL over time.

The floor effect, in turn, reflects the percentage of subjects who score at the lowest levels of the measure. This type of asymmetric distribution makes it hard to detect the worsening in the assessed subjects' perceived HRQoL ${ }^{(17)}$. A slight floor effect (12.4\%) was observed among hypertensive patients, only in relation to the domain Physical Impact of the Disease - Symptoms, and 
this effect was even smaller than that verified among patients with coronary artery diseases $(49.0 \%)^{(15)}$.

The investigation of the ceiling and floor effects is important because, if observed in many domains, these effects can lead to the limitation of another psychometric property: responsiveness. This property, also important, is related to the instrument's ability to detect and estimate the magnitude of change in the health status over time ${ }^{(20)}$.

Whereas one of the methods for assessing responsiveness consists of an approach based on the longitudinal distribution of the sample, any reduction in the variability of the scores, that is, ceiling and floor effects can minimize the sensibility to detect differences and the responsiveness to change ${ }^{(21-22)}$.

Another property involved in the feasibility of the responsiveness assessment of an instrument is the demonstration of its temporal stability. Within a certain range, which is variable according to the studied concept, it is important that the subjects' answers to the instrument do not vary substantially, since there is no greater modification factor that may affect their perception of the studied concept. This property is named temporal stability and was assessed in the range 7 to 21 days in this study. High levels of consistency between the test/retest were observed, in relation to the total score as well as all domains of the IDCV.

Thus, the absence of the ceiling and floor effects for the total score and for most of the domains of the IDCV, as well as the strong evidence of temporal stability, confirm the development of subsequent studies to assess the responsiveness of the IDCV, in the light of clinical changes concerning hypertensive patients.

The IDCV also presented evidence of being composed of homogeneous and correlated items, that is, of internal consistency, which was shown by the values of the Cronbach alpha coefficient for the IDCV as a whole $(\alpha=0.83$ ) and for two of its domains: Physical Impact of the Disease - Symptoms $(\alpha=0.78)$ and Social and Emotional Impact of the Disease $(\alpha=0.74)$. The Impact of the Disease on the Daily Activities domain presented alpha coefficient lower than 0.70 but higher than 0.50 , which also allows the interpretation of its data. This was not observed for the Adjustment to the Disease domain which, as shown by other previous studies with the use of the IDCV ${ }^{(14-15)}$, presented low homogeneity. This is a domain constituted by only two items, which reduces the variability of its score. In addition, the development characteristic of these two items can cause double interpretation and, as a result, inconsistency in the scores given by the patient to answer the question. Item 1 (After I got a heart problem, I started to pay more attention to my health) can be interpreted ambiguously as a good or bad outcome. In turn, item 8 (My sexual life remained the same as before I got the heart problem), may hinder the assessment of the outcome, since it does not show any mention to sexual life before the development of the disease.

Besides low internal consistency, the items of this domain presented a very low correlation with the total score of the instrument, and it was the only one to show a ceiling effect.

The study findings show similar findings concerning the feasibility of the IDCV in other groups presenting cardiovascular diseases, which reiterates the recommendation to review or exclude the items that compose this domain.

\section{Conclusion}

The use of the IDCV in hypertensive patients showed to be feasible, acceptable and potentially sensitive to detect worsening or improvement in the perceived disease impact evidenced by the absence of ceiling and floor effect in the total score of the IDCV and in most of its domains. The findings indicate that the instrument is reliable in relation to temporal stability and internal consistency. The validity properties of the IDCV in hypertensive patients will be disclosed in a subsequent article.

\section{Acknowledgement}

To professor Cleonice Guedes Pavan for her attention and assistance with the grammatical review of this article.

\section{References}

1. Chobanian AV. Improved hypertension Control: cause for some celebration. JAMA. 2010;303(20):2082-3.

2. Costa JV, Silva ARV, Moura IH, Carvalho RBN, Bernardes LE, Almeida PC. An analysis of risk factors for arterial hypertension in adolescent students. Rev. Latino-Am. Enfermagem. mar-abr 2012;20(2): 289-95.

3. Sociedade Brasileira de Cardiologia. VI Diretrizes Brasileiras de Hipertensão Arterial. Rev Bras Hipertens. 2010;17(1):7-10.

4. Ministério da Saúde (BR). Datasus. Morbidade Hospitalar do SUS por local de internação [Internet]. Ministério da Saúde, 2011. [acesso 10 jun 2013]. 
Disponível em: http://tabnet.datasus.gov.br/cgi/tabnet. exe?idb2011/g02.def

5. Pilger $\mathrm{C}$, Menon MH, Mathias TAF. Socio-demographic and health characteristics of elderly individuals: support for health services. Rev. Latino-Am. Enfermagem. setout $2011 ; 19(5): 1230-8$.

6. Palhares LC, Gallani MC, Gemignani T, Matos-Souza JR, Ubaid-Girioli S, Moreno H Jr, et al. Quality of life, dyspnea and ventricular function in patients with hypertension. J Adv Nurs. 2010;66(10):2287-96.

7. Wang R, Zhao Y, Heb X, Maa X, Yana X, Sun Y, et al. Impact of hypertension on health-related quality of life in a population-based study in Shanghai. China Public Health. 2009;123: 534-9.

8. Zygmuntowicz M, Owczarek A, Elibol A, Chudek J. Comorbidities and the quality of life in hypertensive patients. Pol Arch Med Wewn. 2012;122(7-8):333-40.

9. Roca-Cusachs A, Ametla J, Calero S, Comas O, Fernández M, Lospaus $R$, et al. Calidad de vida en la hipertensión arterial. Med Clin.1992;98:486-90.

10. Badia X, Roca-Cusachs A, Dalfó A, Gascón G, Abellán J, Lahoz R, et al. Validation of the short form of the Spanish hypertension Quality of Life Questionnaire (MINICHAL). Clin Ther. 2002;24(12):2137-54.

11. Tavares DMS, Martins NPF,Dias FA, Diniz MA. Qualidade de Vida em Idosos com e sem hipertensão arterial. Rev Eletr Enferm. [Internet] 2011 [acesso 15 ago 2011]; 13(2). Disponível em: http://www.fen.ufg. br/revista/v13/n2/v13n2a07.htm

12. Muszalik M, Dijkstra A, Kedziora-Kornatowska K, Zielisnka-Wieczkowska $\mathrm{H}$, Kornatowski T. Independence of elderly patients with arterial hypertension in fulfilling their needs, in the aspect functional assessment and quality of life (QoL). Arch Gerontol Geriatrics. 2011;52:204-9.

13. Padilha KM, Gallani MGBJ, Colombo RCR. Validity of an instrument to measure the impact of valve heart disease on the patient's daily life. J Clin Nurs. 2007;16(7):1285-91.

14. Padilha KM, Gallani MCBJ, Colombo RCR. Development of an instrument to measure beliefs and attitudes from heart valve disease patients. Rev. LatinoAm. Enfermagem. 2004;2:453-9.

15. Santos RAB, Rodrigues RCM, Padilha KM, Rodrigues SLL, Spana TM, Gallani MCBJ. Validation of an instrument to measure the impact of coronary disease on patient's daily life. J Clin Nurs. 2012;21(3-4):485-94.

16. Mokkink LB, Terwee CB, Patrick DL, Alonso J, Stratford PW, Knol DL, et al. The COSMIN study reached international consensus on taxonomy, terminology, and definitions of measurement properties for healthrelated patient-reported outcomes. J Clin Epidemiol. 2010;63(7):737-45

17. Bennett SJ, Oldridge NB, Eckert GJ, Embree Jl, Browning S, Hou N. Discriminant properties of commonly used quality of life measures in heart failure. Qual Life Res. 2002;11(4):349-59.

18. McHorney CA, Ware JE, Lu JFR, Sherbourne CD. The MOS 36-item short-form health survey (SF-36): Tests of data quality, scaling assumptions and reliability across diverse patient groups. Med Care.1994;32:40-66.

19. Nunnally JC. Psychometric Theory. New York: McGraw-Hill; 1978. $701 \mathrm{p}$.

20. Fayers PM, Machin D. Quality of life: assessment, analysis and interpretation. England: John Wiley; 2007. 544 p.

21. Eurich DT, Johnson JA, Reid KJ, Spertus JA. Assessing responsiveness of generic and specific health related quality of life measures in heart failure. Health Qual Life Outcomes. 2006;24(4):89.

22. Fries J, Rose M, Krishnan E The PROMIS of better outcome assessment: responsiveness, floor and ceiling effects, and Internet administration. J Rheumatol. 2011;38(8):1759-64.
Received: Sept. $7^{\text {th }} 2012$ Accepted: June $25^{\text {th }} 2013$ 